\title{
Review on the Major Challenges and Difficulties of Farm Animal Cloning
}

\author{
Tekalign Tadesse $^{1^{*}} \quad$ Selamu Abraham ${ }^{1} \quad$ Hailegabriel Bedada $^{2}$ \\ 1.College of Agriculture and forestry, Mettu University, P.O. Box 318, Bedele, Ethiopia \\ 2.College of Veterinary Medicine, Samara University, P.O. Box, 132, Samara, Ethiopia
}

\begin{abstract}
Developments in biotechnologywould provide many new opportunities for livestock agriculture, human medicine, and animal conservation. Nuclear cloning involves the production of animals that are genetically identical to the donor cells used in a technique known as nuclear transfer. However, at present it is an inefficient process in farm animal and small number of the embryos transferred to the reproductive tracts of recipient mother result in healthy, long-term surviving clones. Recent cloning research also reveals high failure rates, premature deaths, and dysfunctioning of internal organs.Food products from healthy clones, i.e. meat or milk, did not differ from products from healthy conventionally bred animals. Even though the food products of cloned animals showed no differences with conventional offspring or products,throughout the world there is significant public opposition to the introduction of meat and milk from cloned animals and their progeny into the food supply. Cloning also threatens the welfare of surrogate mothers, the underlying health of the animals and the next generation, the consequential effect on food safety are critical aspects that require investigation to gain regulatory and consumer acceptance.Data on clones of farmed species for food production other than cattle and pigs have remained limited and do not allow for assessment of food safety or animal health and welfare aspects.

Keywords: Biotechnology, Cloning, Food safety, Nuclear transfer, Trans generational effects,
\end{abstract}

\section{Introduction}

Assisted reproductive techniques such as artificial insemination, embryos transfer, in vitro fertilization, embryo micromanipulation and cloning have been developed to obtain offspring from genetically individuals or infertile animals (Andrabi and Maxwell, 2007).Cloning refers to producing genetically identical individual to donor cells and copying gene which involves the creation of individual that drives its genes from a single other individual; it is also referred to as asexual reproduction. Cloning is a powerful technique and potentially it could be used for multiplication of elite animals, conservation as well as propagation of endangered species, to minimize the genetic variation in experimental animal and for the production of stem cells for therapeutic purposes, as therapeutic cloning (Das et al., 2003).

Cloning holds the promise of by passing conventional breeding procedures to allow creation of thousands of precise duplicates of genetically engineered animals. In remote areas, where sampling and storage of adequate samples of semen and embryos is not practical, one could use clone samples from diverse animals for conservation of the available genetic diversity. The local breeds may contain valuable genes that confer adaptation, especially to heat tolerance or disease resistance, and there is an urgent need to prevent their extinction which can achieve by cloning techniques (Duszewska and Reklewski, 2007).

Most recently, there is growing scientific and public interest in using nuclear transfer techniques to facilitate production improvement and the rescue of endangered species, or even to restore them after the extinction of intact organisms (Rudenko et al., 2004).Despiteall the efforts in cloning, there arelow efficiency of cloning and high incidence of developmental abnormalities of cloned animals. Therefore the purpose of this review is to compile available literatures on challenges and difficultiesattributable to the inefficiency of application associated with producingcloned animals from nuclear transfer.

\section{Challenges of Cloning}

There are many technical challenges related to current technologies used in animal cloning,the adverse effects observed are related to systemic disturbances in the regulation of the genome and cannot be confined to single genetic information. Various effects are summarized under the expression 'Large Offspring Syndrome' (LOS), but these effects have many differing causes and a broad range of symptoms. These technical problems and observed adverse effects give rise to questions concerning food safety, animal welfare and the biological integrity of cloned animals (EGE,2008).

\subsection{Animal welfare}

Cloning research reveals abnormalities and high failure rates, problems widely acknowledged by scientists in the field and potentially indicative of poor animal welfare (Han etal., 2003).The health and welfare of a significant proportion of clones, mainly within the young period for bovines and perinatal period for pigs, have been found to be adversely affected, often severely and with a fatal outcome (EFSA, 2008). The list of problems from which 
clones have suffered is extensive, including diabetes, enlarged tongues, malformed faces, intestinal blockages, shortened tendons, deformed feet, weakened immune systems, respiratory distress, circulatory problems, and dysfunctional hearts, brains, livers, and kidneys (Panarace et al.,2007).

Cloning also threatens the welfare of surrogate mothers, most exhibited placental abnormalities that pose serious health risks not only to the developing fetus and offspring, but also to the surrogate mothers carrying the pregnancies, and have resulted in the deaths of both the fetuses and the surrogate mothers (Humpherys et al., 2002).

As the animal welfare group Compassion in World Farming points out at EGE there are several issues where cloning procedures are concerned, Invasive medical interventions at the level of donor animals, invasive medical interventions as for oocyte extraction in some animal species, suffering caused to surrogate mothers, abnormal foetal development and late pregnancy mortality (D'Silva, 2007).

\subsection{Public and social acceptance}

Many peoples were concerned that cloning could result in food that was unsafe for human consumption. This was partly a function of the perceived high incidence of miscarriages and deformed and short-lived offspring resulting from the process. It was also because of a fear that the process of cloning might somehow create new diseases or affect the food in a way that would be harmful to humans. Moreover, the negative impact on human health and wellbeing may only become apparent at some point in the future (EFSA, 2009).

Public opinion against cloning is apparent throughout the world. According to survey conducted in 2008, $61 \%$ of European citizens believe the cloning of animals to be "morally wrong (The Gallup Organization, 2008). In addition one survey in America showed that $64 \%$ of Americans think cloning is "morally wrong," and another $63 \%$ would not buy cloned food even it were labeled as "safe" (Tucker-Foreman, 2012).

Cloning has given rise to a massive ethical debate, including reports by bioethics committees and many books and articles. There are few enthusiastic advocates of cloning, but a number of bioethicists have tried to show that popular responses and even the more sophisticated philosophical arguments against cloning are naive, and cannot be sustained. In a similar, defensive way, liberals have argued that while cloning may not be very desirable, we should not stop other people from doing it, because that would interfere with freedom (Jaenisch, 2003).

\subsection{Food safety}

The composition of food products derived from clones have found that they have the same composition as milk or meat from conventionally-produced animals. Milk and meat from clones produced by embryo splitting and nuclear transfer of embryonic cells have been entering the human food supply for over 20 years with no evidence of problems (Takahashi and Ito, 2004). As there is no fundamental reason to suspect that clones will produce novel toxins or allergens, the main underlying food safety concern was whether the nuclear transfer cloning process results in subtle changes in the composition of animal food products (Rudenko et al., 2004).

In 2008 European Food Safety stated that there was no clear evidence to suggest the difference between food products from cloned and conventionally bred animals on the ground of food safety, but public debate lead review of scientific investigationand again in 2011 they concluded that there was no scientific evidence to suggest that cloned meat or milk could not be eatensafely, but restricted that alicense for the sale products was necessary and currently, there is no existing test for the detection of the characteristics cloned or its offspring (EFSA, 2008).

\section{Difficulties of Cloning}

\subsection{Parturition difficulties (Dystocia)}

Because cloned fetuses are often abnormally large, labor and delivery are likely to be painful and stressful, and the mother is less likely to survive the pregnancy. In one published study describing a cattle cloning project, 3 of 12 surrogate mothers died during pregnancy. Intervention is often believed necessary to deliver cloned offspring, as gestation length in nuclear transfer pregnancies is typically prolonged and the birth weight of cloned calves may be $25 \%$ heavier than normal(Turner, 2002).

Newborn cloned calves display functional adrenal glands, so this extended gestation may be due to failure of the placentae to respond to fetal cortisol near term or to a lack of adrenocorticotropic hormone release from the fetus and oversized cloned offspring add to the birth complications (Chavatte-Palmer et al., 2002).At agriculture research, the occurrence of prolonged gestation and the risk of dystocia initially prompted the delivery of clones by elective caesarean-section, following a brief exposure to exogenous corticosteroids (Rhind et al., 2004).

\subsection{Placental abnormalities}

A failure of the placenta to develop and function correctly is a common feature amongst clones and the majority of early pregnancy failures, before placentome formation, are attributed to an inadequate transition from yolk sac 
to allantoic-derived nutrition, with poor allantoic vascularization in sheep (De-Sousa et al., 2001).

Furthermore, there is reported evidence of immunological rejection contributing to early embryonic loss (Hill et al., 2002). Typically in cattle, $50 \%$ to $70 \%$ of pregnancies at day 50 are lost throughout the remainder of gestation and up to term. This is in stark contrast to only $0 \%$ to

$5 \%$ loss with artificial insemination or natural mating over the same period (Lee et al., 2004). In extreme cases, placentomes are entirely absent at day 50, shortly thereafter, these pregnancies fail. More commonly, cloned placentae only have half the normal number of placentomes, display compensatory overgrowth and are edematous. Of particular concern are the losses in the second half of gestation; especially the occurrence of hydroallantois, i.e. the excess accumulation of fluid within the allantois (Former, 2005). Abnormal pregnancy development could be determined by measuring specific components present in maternal serum with early detection allowing early elective abortion (Chesne et al., 2002).

\subsection{Post-natal viability (death)}

A study showed that around $80 \%$ of cloned calves delivered at term are alive after $24 \mathrm{~h}$. Two-thirds of the mortality within this period is due to a spinal fracture syndrome through the cranial epiphyseal plate of the first lumbar vertebrae or to deaths that occurred either in uterus or from dystocia (Wells et al., 2004). Surviving newborn clones have altered neonatal metabolism and physiology, possibly due to placental abnormalities, and it takes time for these processes to adjust to normal. Typically an additional $15 \%$ of calves initially born alive die before weaning (Chavatte-Palmer et al., 2002). The most common mortality factors during this period are gastroenteritis and umbilical infections. Other abnormalities noted include defects in the cardiovascular, musculoskeletal and neurological systems, as well as susceptibility to lung infections and digestive disorders Lee et al., 2004). The proportion of cloned calves that survive to weaning is significantly greater for those derived from quiescent $\mathrm{G}_{0}$ donor cells (81\%) than for those derived from $\mathrm{G}_{1}$ cells (50\%) (Wells et al., 2003).

\subsection{Trans-generational effects}

Experiments on ratshow that epigenetic effects can be found over three following generations, transgenerational epigenetic inheritance in response to various conditions has been documented in many eukaryotes and may play an important role in mammals. In particular, environmental influences such as stress extreme temperature and infectious disease may induce a number of epigenetic modifications leading to the silencing or activation of specific genes, especially when pregnant females are maintained in conditions resulting in stress in the dam and foetus. The epigenetic modifications observed in the offspring of those pregnancies may then be transmitted to their progeny. These phenomena, which are considered as mechanisms of adaptation, have been found to be reversible after three generations in rats (EFSA, 2009).

In the mating of cloned females with cloned males, with these mating in sheep, cattle and mice there is no evidence of the placental abnormalities and only large birth weights is recorded in the clone generation. It has also been claimed that the obese phenotype observed in cumulus cell mouse clones is not heritable following mating with cloned males derived from fibroblasts of the same mouse strain (Ogura et al., 2002). The most convincing evidence for the lack of transmission of any obvious deleterious recessive genetic or epigenetic trait has been provided following the mating of cloned male and cloned female mice obtained from the same cell line. The resulting offspring were phenotypically normal, lacking the fetal and placental overgrowth and openeyelids-at-birth characteristic of their cloned parents (Oback et al., 2003).

Clone-associated phenotypes are not transmitted to offspring following sexual reproduction, implies that they are epigenetic in nature and that any errors in the surviving clones appear to be reset or corrected during gametogenesis. It is critical to investigate this phenomenon more thoroughly, as evidence exists for the germ line transmission of epigenetic states at various endogenous loci and in more artificial situations, following nuclearcytoplasmic incompatibility (Ogonuki et al., 2002).

\section{Conclusion and Recommendations}

Genetic engineering of animals has made its mark on the global stage of biotechnology. Particularly Cloning has the potential to improve the efficiency of trans-genesis in these applications, as well as a role for the multiplication of animals of proven production.Somatic Cell Nuclear Transfer can produce healthy clones, but a portion of the animal clones suffered from developmental abnormalities likely due to epigenetic dysregulation and died at various stages of development. For some of the live animal clones, in particular calves and piglets, health and welfare were compromised specifically within the perinatal and juvenile period. Also some of the surrogate dams were affected due to abnormal pregnancies. High failure rates, defects, disabilities, and the premature deaths of both surrogate mothers and offspring have weighed down the application of biotechnology to farm animals. The decisions we make now about genetic engineering and cloning will have profound effects on the future of our relationship to farm animals and to farming. Despite the present limitations of cloning, the milk and meat from these livestock animals does not appear to be materially different from those of 
conventionally bred animals. Based on the above review and conclusion, the following recommendations are forwarded:

$>$ If the application and acceptability of this emerging technology are to be improved, it is important to understand the biology behind nuclear cloning so as to improve the health and viability of the cloned animals produced and of their surrogate mothers.

$>$ Even though vast research efforts are being focused on trying to better understand the source of the problems, experts and veterinary professional need to better understand the medical problems associated with cloned animals in order to develop more effective treatments to reduce pregnancy loss and neonatal morbidity and mortality levels.

$>$ It is desirable that the health and wellbeing of cloned animals should be equal to non-clones and that any deficit should be minimized and thoroughly justified in terms of the benefits expected from the application. Achieving this goal will only result from improvements in the efficiency of the cloning process. This is the prime concern of many international organizations recently workingin this field.

\section{Reference}

Andrabi, S.M. and Maxwell, W.M. (2007). A review on reproductive biotechnologies for conservation of endangered mammalian species. Anim Reprod Sci. 99: 223-243.

Chavatte-Palmer, P., Heyman Y., Richard C., Monget P., Le-Bourhis D., Kann G., Chilliard Y., Vignon X. \& Renard J.P. (2002): Clinical, hormonal and hematologic characteristics of bovine calves derived from nuclei from somatic cells. Biol. Reprod., 66, 1596-1603.

Chesne, P., Adenot, P., Viglietta, C., Baratte, M., Boulanger, L. and Renard, J. (2002): Cloned rabbits produced by nuclear transfer from adult somatic cells. Nature Biotechno. 20: 366-369.

D'Silva, J. (2007): The Ethical Aspects of Animal Cloning for Food Supply, Compassion in World Farming (CIWF) organization.

Das, S.K., Majumdar, A.C. and Sharma, G.T. (2003): In vitro development of reconstructed goat oocyte after somatic cell nuclear transfer with fetal fibroblast cells. Small Rumin. Res., 48: 217-225.

De-Sousa P.A., King T., Harkness L., Young L.E., Walker S.K. \& Wilmut I. (2001): Evaluation of gestational deficiencies in cloned sheep fetuses and placentae. Biol. Reprod., 65, 23-30.

Duszewska, A. and Reklewski, Z. (2007): Uzyskiwanie zarodków zwierz't gospodarskich in vitro (Obtaining in vitro embryos from farm animals). Med. Weteryna., 63: 1522-1525.

EFSA, (2008) Statement of EFSA prepared by the Scientific Committee and Advisory Forum Unit on Further Advice on the Implications of Animal Cloning (SCNT). The EFSA Journal.1-9.

EFSA, (2009): Statement of EFSA prepared by the Scientific Committee and Advisory Forum Unit on Further Advice on the Implications of Animal Cloning (SCNT). The EFSA Journal RN 319, 1-15.

EGE, The European Group on Ethics in Science and New Technologies to the European Commission (2008): Ethical aspects of animal cloning for food supply, opinion number 23. Farming Trust.

Former, F.J. (2005): Attempts to produce monozygotic quadruplets in cattle by blastomere separation. Vet Rec., 2: 234-254.

The Gallup Organization, (2008). Flash Eurobarometer 238: Europeans' attitudes towards animal cloning.An HSI Report: Welfare Issues with Genetic Engineering and Cloning of Farm Animals. 2, 1-9.

Han,Y.M., Kang, Y.K., Koo, D.B. and Lee, K.K. (2003): Nuclear reprogramming of cloned embryos produced in vitro. Therio. 59:33-44.

Hill J.R., Schlafer D.H., Fisher P.J. \& Davies C.J. (2002): Abnormal expression of trophoblast major histocompatibility complex class I antigens in cloned bovine pregnancies is associated with a pronounced endometrial lymphocytic response. Biol. Reprod.67, 55-63.

Humpherys, D., Eggan, K., Akutsu, H., Friedman, A., Hochedlinger, K., Yanagimachi, R., Lander, E., Golub T.and Jaenisch R. (2002): Abnormal gene expression in cloned mice derived from embryonic stem cell and cumulus cell nuclei. Proc. Natl. Acad. Sci., 99: 1289-1294.

Jaenisch, R. (2003): The biology of nuclear cloning and the potential of embryonic stem cells for transplantation therapy, Background paper for the President's Commission on Bioethics, available at: http://www.bioethics.gov.

Lee R.S., Peterson A.J., Donnison M.J., Ravelich S., Ledgard A.M., Li N., Oliver J.E., Miller AL, Tucker F.C., Breier B. \& Wells D.N. (2004): Cloned cattle fetuses with the same nuclear genetics are more variable than contemporary half-siblings resulting from artificial insemination and exhibit fetal and placental growth deregulation even in the first trimester. Biol. Reprod., 70, 1-11.

Oback B., Wiersema A.T., Gaynor P., Laible G., Tucker F.C., Oliver J.E., Miller A.L., Troskie H.E., Wilson K.L., Forsyth J.T., Berg M.C., Cockrem K., and McMillan V., Tervit H.R. \& Wells D.N. (2003): Cloned cattle derived from a novel zona-free embryo reconstruction system. Cloning Stem Cells, 5, 3-12. 
Ogonuki N., Inoue K., Yamamoto Y., Noguchi Y., Tanemura K., Suzuki O., Nakayama H., Doi K., Ohtomo Y., and Satoh M., Nishida A. \& Ogura A. (2002): Early death of mice cloned from somatic cells. Nature Gene. 30, 253-254.

Ogura A., Inoue K., Ogonuki N., Lee J., Kohda T. \& Ishino F. (2002): Phenotypic effects of somatic cell cloning in the mouse. Cloning Stem Cells, 4, 397-405.

Panarace, M., Aguero, J. and Garrote, M. (2007): How healthy are clones and their progeny. Therio.67:142-51.

Rhind S., Cui W., King T., Ritchie W., Wylie D. \& Wilmut I. (2004). Dolly: a final report. Reprod. Fertil. Dev., 16, 156.

Rudenko,L., Matheson,J., Adams,A., Dubbin,E. and Greenlees,K (2004): Food consumption risks associated with animal clones. Clon. Stem Cel. 6: 79-93.

Takahashi, S. and Ito,Y. (2004): Evaluation of meat products from cloned cattle: Biological and biochemical properties. Clon. Stem Cells. 6:165-171.

Tucker-Foreman, C. (2012): Public interest perspective on animal cloning. In: Animal cloning and the production of food products: Perspectives from the food chain. Proceedings from a workshop sponsored by the Pew Initiative on Food and Biotechnology and the Center for Veterinary Medicine of the U.S. Food and Drug Administration.

Turner, J. (2002): The Gene and the Stable Door biotechnology and farm animals. A Report for the Compassion in World,January 2002.

Wells D., Laible, G., Tucker, F., Miller, A., Oliver, J., Xiang, T., Forsyth, J., Berg, M., Tervit, H. and Oback, B. (2003): Coordination between donor cell type and cell cycle stage improves nuclear cloning efficiency in cattle. Therio.59: 45-59.

Wells D.N., Forsyth. J.T., McMillan V. \& Oback B. (2004): Review: the health of somatic cell cloned cattle and their offspring, Cloning Stem Cells.6, 101-110. 